\title{
STUDY OF THE EFFICIENCY OF ELECTROFLOTATION PROCESS ON A MIXTURE OF HEAVY HYDROXIDES AND NONFERROUS METALS IN VARIOUS ELECTROLYTES
}

\author{
Thu Aung HEIN, Pyae AUNG, Zaw Htay THAN, Artem Vladimirovich KOLESNIKOV \\ Mendeleev University of Chemical Technology of Russia, Miusskaya pl. 9, Moscow, 125047 Russia, \\ spiritlay@yandex.ru
}

https://doi.org/10.37904/metal.2020.3600

\begin{abstract}
The features of electroflotation extraction of a mixture of heavy hydroxides and non-ferrous metals $\left(\mathrm{Fe}^{2+}, \mathrm{Ni}^{2+}\right.$, $\left.\mathrm{Zn}^{2+}, \mathrm{Co}^{2+}, \mathrm{Cu}^{2+}\right)$ from a five-component system in the presence of various background electrolytes were studied. The influence of the nature of various background electrolytes on the kinetics of electroflotation extraction of the mixture of the studied hydroxides at $\mathrm{pH}=10$ was established. It is shown that the addition of $\mathrm{NaCl}$ electrolyte can increase the efficiency and stabilize the electroflotation process of extraction of hard-todissolve heavy and non-ferrous metal compounds as part of multi-component systems from the wastewater of various electroplating plants, the recovery rate can reach to $99 \%$.
\end{abstract}

Keywords: Electroflotation, filtration, waste water, non-ferrous metals

\section{INTRODUCTION}

Industrial and urban wastewater potentially contains a wide variety of pollutants, some of which are difficult to remove in conventional water and wastewater treatment plants. In this regard, several alternative methods for cleaning contaminated water have been proposed to ensure the safety of water for human consumption and to meet environmental needs. Among the methods used to effectively separate the solid phase from the liquid or one liquid phase from another, electroflotation (EF) is one of the most promising modern technologies [1].

One of the actual problems is to increase the efficiency of the process of electroflotation (EF) extraction of metal hydroxides in multi-component systems. The main approach of electroflotation treatment is associated with the formation of metal hydroxides at the first stage, followed by separation of the dispersed phase in the process of sedimentation, flotation, filtration [2].

In the works performed earlier [2,3], it was shown that the presence of organic components of different nature in wastewater affects the efficiency of solid-liquid separation processes. Some generalizing materials are presented in Table 1.

Table 1 Efficiency of solid / liquid separation processes in the presence of organic components

\begin{tabular}{|c|c|c|c|c|}
\hline $\begin{array}{c}\text { The stage of separation of } \\
\text { solid phase/liquid }\end{array}$ & Surfactant & Emulsion & Solvent & $\begin{array}{c}\text { Polymer electrolyte } \\
\text { (flocculant) }\end{array}$ \\
\hline Sedimentation & Reduces & Reduces & No effect & Raises \\
\hline Microfiltration & Reduces & Reduces & Complicates & Reduces \\
\hline Flotation & Raises & Raises & No effect & Raises \\
\hline Electroflotation & Raises & Raises & No effect & Raises \\
\hline
\end{tabular}

The analysis shows that for waste water containing surfactants, emulsions, solvents, flotation and electroflotation has an advantage in the processes of extraction of suspended substances. 
The purpose of this work is to study the main regularities of the process of electroflotation extraction of a mixture of heavy and non-ferrous metal hydroxides in various electrolytes $\mathrm{Na}_{2} \mathrm{SO}_{4}, \mathrm{NaCl}, \mathrm{NaNO}_{3}$. As well as determining the optimal conditions for the extraction of a mixture of heavy and non-ferrous metal hydroxides with minimal energy consumption and process time, increasing the processing efficiency by using the electroflotation process and filtration.

Model wastewater treatment was carried out by electroflotation using a non-flowing laboratory installation according to the method described in the literature $[4,5]$.

\section{EXPERIMENTAL}

Studies were carried out on model solutions containing iron, Nickel, zinc, cobalt and copper ions and with a given concentration of metal ions, $\mathrm{Fe}^{2+}, \mathrm{Ni}^{2+}, \mathrm{Zn}^{2+}, \mathrm{Co}^{2+}, \mathrm{Cu}^{2+} 20 \mathrm{mg} / \mathrm{l}\left(\sum \mathrm{Me} 100 \mathrm{mg} / \mathrm{l}\right)$ were added sequentially $\mathrm{Na}_{2} \mathrm{SO}_{4}, \mathrm{NaCl}, \mathrm{NaNO}_{3}, \mathrm{Na}_{3} \mathrm{PO}_{4}$, and $\mathrm{Na}_{2} \mathrm{CO}_{3}$ were used as an electrolyte to create a constant ionic force at a concentration of $1 \mathrm{~g} / \mathrm{l}$. The concentration of metal ions was determined by atomic adsorption method in the D. M. Mendeleev Central research center. To completely dissolve the hydroxides after sampling, several milliliters of concentrated $\mathrm{HNO}_{3}$ were added to the measuring flask.

Model wastewater treatment was performed by electroflotation using a laboratory unit consisting of a direct electric current source HY 1803D, a $500 \mathrm{ml}$ non-flow electroflotator with a cross-sectional area of $10 \mathrm{~cm}^{2}$ and a height of $80 \mathrm{~cm}$ with an insoluble ORTA anode and a cathode made of $12 \mathrm{X} 18 \mathrm{H} 10 \mathrm{~T}$ stainless steel according to a well - known method [6 - 15].

The efficiency of the electroflotation process was estimated by the degree of extraction (deposition) $\alpha(\%)$, which is calculated by the formula:

$\alpha=\frac{\left(C_{i n i}-C_{f i n}\right)}{C_{i n i}} \times 100 \%$,

where: $\alpha$ - degree of extraction (\%); Cini - initial concentration of the dispersed phase in the aqueous medium $(\mathrm{mg} / \mathrm{l})$; $C_{\text {fin }}$ - final concentration of the dispersed phase in the aqueous medium ( $\left.\mathrm{mg} / \mathrm{l}\right)$.

Reagents were used to prepare model solutions: $\mathrm{FeCl}_{2} \mathrm{x}$ $4 \mathrm{H}_{2} \mathrm{O}, \mathrm{NiSO}_{4} \times 7 \mathrm{H}_{2} \mathrm{O}, \mathrm{ZnSO}_{4} \times 7 \mathrm{H}_{2} \mathrm{O}, \mathrm{CoSO}_{4} \times 7 \mathrm{H}_{2} \mathrm{O}$, $\mathrm{CuSO}_{4} \times 5 \mathrm{H}_{2} \mathrm{O}, \mathrm{Na}_{2} \mathrm{SO}_{4}, \mathrm{NaCl}, \mathrm{NaNO}_{3}, \mathrm{Na}_{3} \mathrm{PO}_{4}, \mathrm{Na}_{2} \mathrm{CO}_{3}$, $\mathrm{XH}$. Model solutions were prepared using distilled water. In some cases, after electroflotation cleaning, additional filtration of the solution was carried out using destitute filters "Blue ribbon" TU 2642-001-13927158-2003 (pore diameter $\sim 1 \mu \mathrm{m}$ ).

The diagram of a laboratory electroflotation unit of periodic action is shown in Figure 1.

$\mathrm{Ph}$ control was performed using a $\mathrm{pH}$ meter (ionomer) $\mathrm{pH}$ 410 with standard glass (ESK-1060/7) and silver chloride electrodes. $\mathrm{pH}$ solution was adjusted to the desired value using $\mathrm{NaOH}$ and $\mathrm{H}_{2} \mathrm{SO}_{4}$ solutions the working area of the $\mathrm{pH}=10 \pm 0.2$ units.

In some cases, after electroflotation cleaning, additional filtration of the solution was carried out with the help of decontaminated filters "Blue tape" TY 2642-00113927158-2003 (pore diameter $\sim 1 \mu \mathrm{m}$ ).

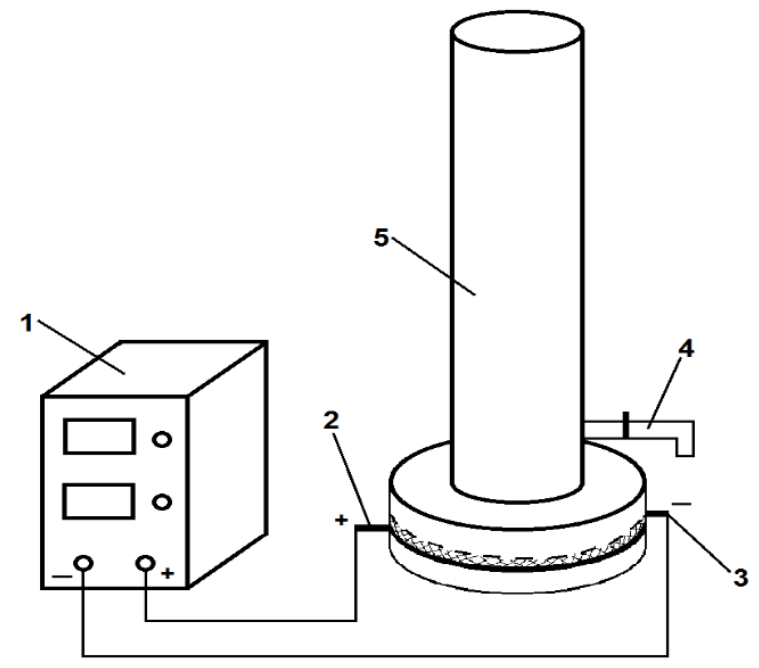

Figure 1 Scheme of a laboratory electroflotation unit of periodic action. 1- direct current source; 2- anode; 3-cathode; 4-valve; 5 - electric flotation column 
In Table 2 experimental results are showing the influence of the nature of the background electrolyte on the kinetics of electroflotation extraction of the mixture of the studied hydroxides at $\mathrm{pH}=10$ and the electroflotation time of 5,10 and 20 minutes.

Table 2 Influence of the nature of the electrolyte on the degree of electroflotation recovery of a mixture of heavy and non-ferrous metal hydroxides

\begin{tabular}{|c|c|c|c|c|c|c|}
\hline \multirow{2}{*}{ Electrolytes } & \multirow{2}{*}{$\begin{array}{c}\text { Electroflotation } \\
\text { time (min) }\end{array}$} & \multicolumn{5}{|c|}{ Extraction degree, $\alpha(\%)$} \\
\hline & & $\mathrm{Fe}$ & $\mathrm{Ni}$ & Zn & Co & $\mathrm{Cu}$ \\
\hline \multirow{3}{*}{$\mathrm{Na}_{2} \mathrm{SO}_{4}$} & 5 & 63 & 84 & 80 & 87 & 82 \\
\hline & 10 & 69 & 96 & 92 & 98 & 93 \\
\hline & 20 & 75 & 96 & 94 & 97 & 95 \\
\hline \multirow{3}{*}{$\mathrm{NaNO}_{3}$} & 5 & 88 & 76 & 90 & 89 & 81 \\
\hline & 10 & 95 & 77 & 96 & 97 & 97 \\
\hline & 20 & 96 & 81 & 97 & 98 & 97 \\
\hline \multirow{3}{*}{$\mathrm{Na}_{3} \mathrm{PO}_{4}$} & 5 & 7 & 10 & 1 & 1 & 1 \\
\hline & 10 & 11 & 28 & 3 & 2 & 3 \\
\hline & 20 & 17 & 37 & 4 & 4 & 6 \\
\hline \multirow{3}{*}{$\mathrm{NaCl}$} & 5 & 92 & 89 & 92 & 95 & 94 \\
\hline & 10 & 94 & 91 & 95 & 98 & 96 \\
\hline & 20 & 96 & 95 & 96 & 99 & 98 \\
\hline \multirow{3}{*}{$\mathrm{Na}_{2} \mathrm{CO}_{3}$} & 5 & 93 & 77 & 93 & 96 & 87 \\
\hline & 10 & 94 & 84 & 95 & 97 & 94 \\
\hline & 20 & 96 & 90 & 97 & 99 & 96 \\
\hline
\end{tabular}

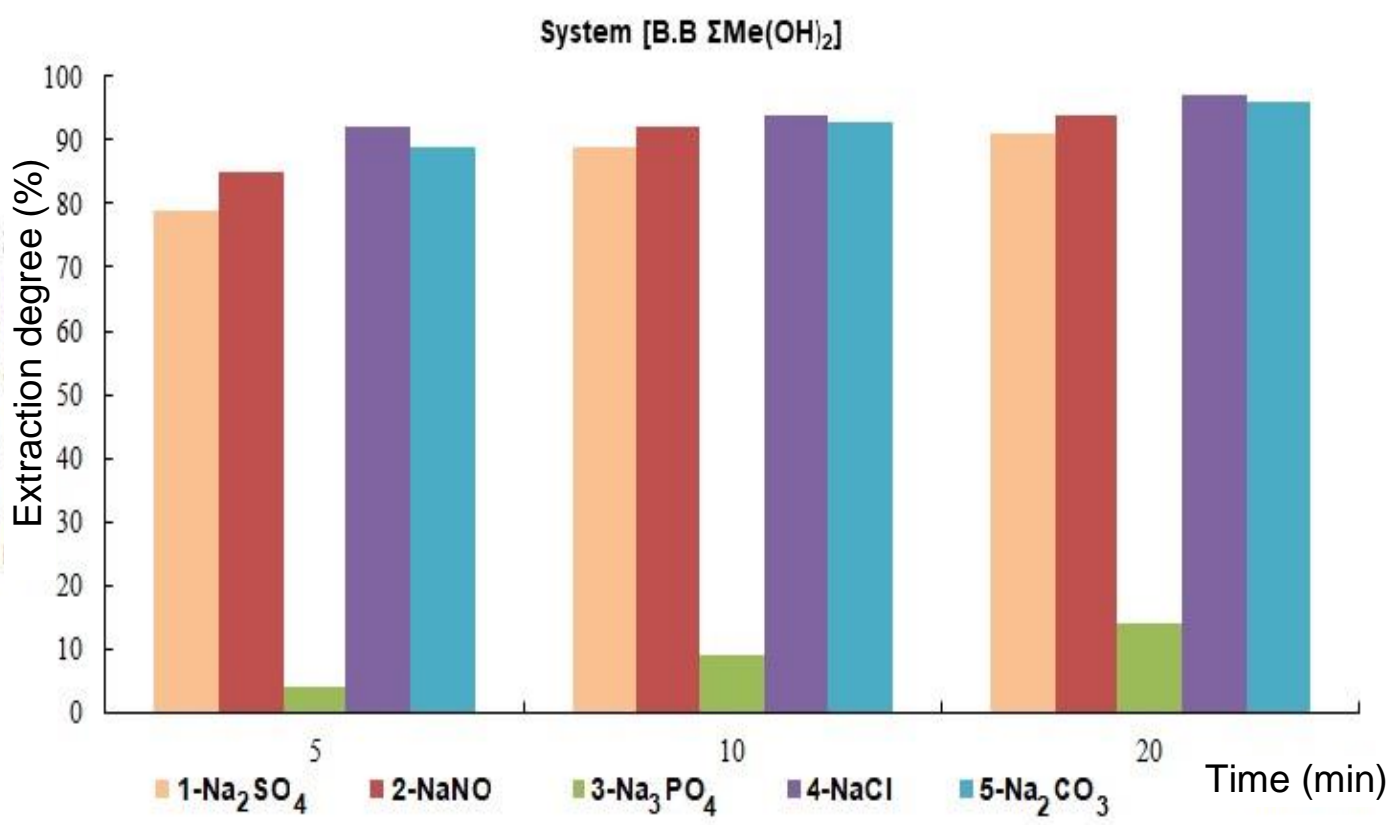

Figure 2 Influence of the nature of the electrolyte on the electroflotation extraction of hard-to-dissolve heavy and non-ferrous metal hydroxides 
Experiment Conditions: $\mathrm{Fe}^{+2}, \mathrm{Ni}^{+2}, \mathrm{Zn}^{+2}, \mathrm{Co}^{+2}, \mathrm{Cu}^{+2}-20 \mathrm{mg} / \mathrm{l}, \Sigma \mathrm{Me} 100 \mathrm{mg} / \mathrm{l} ; \mathrm{C}$ (background electrolyte) $-1 \mathrm{~g} /$; $\mathrm{pH}=10 ; \mathrm{i}_{\mathrm{v}}=0.4 \mathrm{~A} / \mathrm{l}$

The conducted research shows the principal possibility and high efficiency of the process of electroflotation extraction of a mixture of insoluble compounds of iron, nickel, copper, zinc and cobalt in the form of hydroxides.

It is experimentally established Figure 2 that the degree of recovery for each metal differs under certain conditions, the most accurate estimate can be given for the total recovery of ITM. The MPC for Fe, Ni, Zn, Co, and $\mathrm{Cu}$ ions is at the level of $0.01-0.1 \mathrm{mg} / \mathrm{l}$ [1]. Additional filtration after electroflotation allows to achieve a recovery rate of $\alpha=99 \%$ for all hydroxides.

It was found that the highest recovery efficiency (95-99\%) was achieved in the conditions of a chloride background electrolyte, which is explained by the extraction of a mixture of hydroxides.

In the phosphate pool, these metals are present in the form of phosphates, whose low recovery efficiency is due to their small size $(5-10 \mu \mathrm{m})$ and high negative electrokinetic potential $(-35 \mathrm{mV}-40 \mathrm{mV})$.

In the carbonate background, hydrolysis processes occur, difficult-to-dissolve compounds, which also worsen the processes of electroflotation extraction.

\section{CONCLUSION}

The intention of this work is to survey the main regularities of the process of electroflotation extraction of a mixture of heavy and non-ferrous metal hydroxides in various electrolytes $\mathrm{Na}_{2} \mathrm{SO}_{4}, \mathrm{NaCl}, \mathrm{NaNO}_{3}$.

The conducted research shows the possibility of electroflotation extraction of a mixture of heavy and nonferrous metal hydroxides in various electrolytes with an efficiency of $99 \%$.

When using the $\mathrm{Na}_{3} \mathrm{PO}_{4}$ electrolyte, iron, nickel, copper, zinc and cobalt hydroxides are excerpted to a low degree, the recovery rate is $5-20 \%$ in the slightly alkaline region at $\mathrm{pH}=10$.

And when using the $\mathrm{NaCl}$ electrolyte, iron, nickel, copper, zinc and cobalt hydroxides are extracted to a high degree, the recovery rate is $95-99 \%$.

\section{ACKNOWLEDGEMENTS}

I would like to express my deep gratitude to Doctor of technical Sciences, Professor Kolesnikov V.A., my research supervisors, for his patient guidance, enthusiastic encouragement and useful critiques

of this research work. I would also like to thank Mr. Kolesnikov A.V. (Candidate of Technical

Sciences, senior researcher of Technopark "Ecochemical 2000+" Mendeleev, for his advice and assistance in keeping my progress. My grateful thanks are also extended to Ph.D students Mr. Aung Pyae and Mr. Than Zaw Htay, for their help in doing experiment and analysis.

My special thanks are extended to the administrator and organization of the Conference METAL 2020 for invitation.

\section{REFERENCES}

[1] DA MOTA. I. O., DE CASTRO. J.A., CASQUEIRA. R.G., DE OLIVEIRA JUNIOR. A.G. Study of electroflotation method for treatment of wastewater from washing soil contaminated by heavy metals. Journal of Materials Research and Technology. 2015, vol. 4, no. 2. pp. 109.

[2] HEIN, T. A., KOLESNIKOV, V. A. Influence of the nature of surfactants and flocculants on the electroflotation process of extracting a mixture of non-ferrous metal hydroxides from waste water of electrochemical productions. Electroplating and surface treatment. 2018, vol. 16, no. 4, pp. 51-57. 
[3] SHEMI A., HSIEH J., LEE D. Clarification of flexographic wastewater by electrocoagulation and electroflotation. Appita J. 2014, vol. 67, no. 3, pp. 212.

[4] AUNG, P., HEIN, T. A., KOLESNIKOV, A.V. Influence of Decorrdal phosphating composition on electroflotation extraction of hard-to-dissolve $\mathrm{cu}, \mathrm{Ni}, \mathrm{Zn}, \mathrm{Co}, \mathrm{Fe}, \mathrm{Al}$ compounds from wash and waste waters. Electroplating and surface treatment. 2019, vol. 27, no. 2, pp. 31-39.

[5] DAVILA J.A., MACHUCA F., MARRIANGA N. Treatment of vinasses by electrocoagulation-electroflotation using the Taguchi method. Electrochimica Acta. 2011, vol. 56, pp. 7433.

[6] VINOGRADOV S. S. Organization of electroplating. Equipment, calculation of production, rationing. M.: "Globus" 2005, pp 240.

[7] BALMASOV A.V. GRIDCHIN S. N. SHEKHANOV R. F. Electrodeposition of zinc-nickel alloys from alkaline complex electrolytes. Russian journal of chemistry and chemical technology. 2016, vol. 59, no. 1, pp. 51-53.

[8] BALMASOV A.V. GRIDCHIN S. N. RUMYANTSEVA K. E. SHEKHANOV R. F. Electrodeposition of cobalt-Nickel and zinc-Nickel alloys from sulfamate-chloride electrolytes. Chemistry and chemical technology. 2014, vol. 57, no. 8, pp. 47-51.

[9] GHERNAOUT R.D., NACEUR M.W., GHERNAOUT B., A review of electrocoagulation as a promising coagulation process for improved organic and inorganic matters removed by eletrophoresis and electroflotation. Desal. Wat. Treat. 2011, vol. 28, pp. 287-320.

[10] CERQUEIRA A.A., SOUZA P.S.A., MARQUES M.R.C. Effects of direct and alternating current on the treatment of oily water in an electroflocculation process. Braz. J. Chem. Eng. 2014, vol. 31, no. 3, pp. 693.

[11] WANG CHIH-TA, CHOU WEI-LUNG, KUO YI-MING. Removal of COD from laundry wastewater by electrocoagulation/electroflotation. J. Hazardous Mater. 2009, vol. 164, no. 1, pp. 81.

[12] MESHALKIN, V. P., KOLESNIKOV, A.V., KOVALENKO, V. S., GAIDUKOV, E. N. Experimental studies of the efficiency of the electroflotation process for extracting difficult-to-dissolve lanthanum compounds from aqueous solutions. Reports of the Academy of Sciences. 2016, vol. 467, no. 2, pp. 185.

[13] DE OLIVEIRA DA MOTA I., DE CASTRO J. A., DE GO'RS CASQUEIRA R., DE OLIVEIRA JUNIOR A. G. Study of electroflotation method for treatment of wastewater from washing soil contaminated by heavy metals. J. Mater. Res. Technol. 2014, vol. 4, pp. 109-113.

[14] ESFANDYARI, Y., MAHDAVI, Y., SEYEDSALEHI, M., HOSEINI, M., SAFARI, G.H., GHOZIKALI, M.G., KAMANI, H., JAAFARI, J. Degradation and biodegradability improvement of the olive mill wastewater by proxyelectrocoagulation/ electro oxidation-electroflotation process with bipolar aluminium electrodes. Environmental Science and Pollution Research. 2014.

[15] MATIS, K.A. Flotation as a separation process. New York: Wiley. 2015. 